\title{
Mentoring the working nurse: a scoping review
}

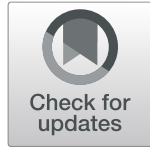

Jerilyn Hoover ${ }^{1,2}$, Adam D. Koon $^{2^{*}}$ (D, Erica N. Rosser ${ }^{2}$ and Krishna D. Rao ${ }^{2}$

\begin{abstract}
Background: Mentoring programs for nurses already in the health workforce are growing in importance. Yet, the settings, goals, scale, and key features of these programs are not widely known.

Objective: To identify and synthesize research on in-service nurse mentoring programs.

Methods: We reviewed nurse mentoring research from six databases. Studies either referred explicitly to in-service nurse mentoring programs, were reviews of such programs, or concerned nurse training/education in which mentoring was an essential component.

Results: We included 69 articles from 11 countries, published from 1995 to 2019. Most articles were from highincome countries $(n=46)$ and in rural areas $(n=22)$. Programs were developed to strengthen clinical care (particularly maternal and neonatal care), promote evidence-based practice, promote retention, support new graduate nurses, and develop nurse leaders. Of the articles with sufficient data, they typically described small programs implemented in one facility $(n=23)$, with up to ten mentors $(n=13)$, with less than 50 mentees $(n=25)$, meeting at least once a month $(n=27)$, and lasting at least a year $(n=24)$. While over half of the studies $(n=36)$ described programs focused almost exclusively on clinical skills acquisition, many $(n=33)$ specified non-clinical professional development activities. Reflective practice featured to a varying extent in many articles $(n=29)$. Very few $(n=6)$ explicitly identified the theoretical basis of their programs.

Conclusions: Although the literature about in-service nurse mentoring comes mostly from small programs in highincome countries, the largest nurse mentoring programs in the world are in low- and middle-income countries. Much can be learned from studying these programs in greater detail. Future research should analyze key features of programs to make models of mentoring more transparent and translatable. If carefully designed and flexibly implemented, in-service nurse mentoring represents an exciting avenue for enhancing the role of nurses and midwives in people-centered health system strengthening.

The contents in this article are those of the authors and do not necessarily reflect the view of the U.S. President's Emergency Plan for AIDS Relief, the U.S. Agency for International Development or the U.S. Government.
\end{abstract}

Keywords: Human Resources for Health, Mentoring, Nursing, Quality of Health Care, Rural Health

\footnotetext{
* Correspondence: AdamKoon@jhu.edu

${ }^{2}$ Department of International Health, Johns Hopkins Bloomberg School of Public Health, 615 N Wolfe St, Baltimore, MD 21205, USA

Full list of author information is available at the end of the article
}

(c) The Author(s). 2020 Open Access This article is licensed under a Creative Commons Attribution 4.0 International License, which permits use, sharing, adaptation, distribution and reproduction in any medium or format, as long as you give appropriate credit to the original author(s) and the source, provide a link to the Creative Commons licence, and indicate if changes were made. The images or other third party material in this article are included in the article's Creative Commons licence, unless indicated otherwise in a credit line to the material. If material is not included in the article's Creative Commons licence and your intended use is not permitted by statutory regulation or exceeds the permitted use, you will need to obtain permission directly from the copyright holder. To view a copy of this licence, visit http://creativecommons.org/licenses/by/4.0/ The Creative Commons Public Domain Dedication waiver (http://creativecommons.org/publicdomain/zero/1.0/) applies to the data made available in this article, unless otherwise stated in a credit line to the data. 


\section{Background}

Several approaches to strengthening heath worker performance have been tried in a variety of settings [1]. Programs focused on financial incentives such as resultsbased financing or pay-for-performance have had limited success in sustaining provider behavior change [2]. Traditional training programs often place health workers in controlled environments during short trainings, which are not very effective for building lasting skills [3]. Centralized trainings in urban areas may particularly limit opportunities for rural health workers [4]. External trainings likely disrupt rural facilities, which may already struggle to provide regular access to care. There is mixed evidence that supportive supervision interventions, particularly in low-income countries, are effective [5]. Additionally, a recent systematic review of strategies to improve the practices of health care providers in lowand middle-income countries found combined training and supervision's effect was larger than either intervention alone, but the quality of evidence was low to moderate [6]. Using job aids such as checklists to strengthen service delivery have also generated mixed results [7].

These challenges are attributable in part to clinical knowledge being difficult to translate into practice [8]. While health workers with more knowledge tend to provide better care, there is usually a gap between their knowledge and the care they provide [9]. Health worker motivation, support from colleagues, and work environment can impact this "know-do" gap [9]. Thus, traditional in-service training programs focused on didactic teaching are likely insufficient for strengthening the quality of clinical skills.

Systemic improvements to quality of care should include nurses because they shape primary care in profound ways [10]. Nurses and midwives make up nearly $50 \%$ of the world's health workforce, promoting health, preventing disease, and delivering care in a variety of settings [11]. Nurses are essential to overall patient quality of care [12] and nurse staffing and education levels impact clinical outcomes $[13,14]$. Yet, structural constraints, such as unsupportive work environments, frequently contribute to job-related stress, burnout, and turnover among nurses, with damaging effects on quality of care [15]. Therefore, practical strategies for effectively educating, supporting, and retaining nurses are prerequisites for universal health coverage [16].

Mentoring nurses already in the health workforce (inservice) is one such strategy. Although mentoring emerged in the nursing literature in the 1980s, there has been significant disagreement about the role of nurse mentors [17]. An interactive social process, mentoring is more expansive than didactic training, coaching, or supervision [4]. For this paper, we suggest that mentoring involves establishing "a relationship between two people that has the specific purpose of one assisting the other to grow and develop and to increase their role effectiveness." [18]

Despite a lack of clear models for nurse mentoring and differing views about the degree to which the concepts of precepting, mentoring, and clinical supervision overlap [19], programs have been designed and implemented in low-, middle-, and high-income countries. If health officials are to consider in-service nurse mentoring as a viable workforce development strategy, they need a clear empirical basis for making decisions. There are no recent reviews about nurse mentoring specifically, and existing reviews are either out-dated [17] or define mentoring very narrowly [4]. We address this gap by identifying and synthesizing the literature about nurse mentoring in health service delivery settings. As researchers evaluating a large nurse mentoring program in a rural state in India, we were particularly interested in which countries and geographic settings were most represented in existing literature. We adopted a flexible and broad research question: "What is known from the existing literature about in-service nurse mentoring programs?" This analysis will shed light on the design and mechanics of nurse mentoring programs, including their aims, size, setting, and content.

\section{Methods}

A literature review was conducted using Arksey and O'Malley's methodology for scoping reviews [20]. While scoping reviews differ from systematic reviews, the Preferred Reporting Items for Systematic Reviews and Meta-Analyses (PRISMA) guidelines were consulted and adhered to (where applicable) to ensure rigor [21]. A research librarian was consulted, and six databases were searched in September 2019 using the terms: "nurs*" and "mentor". The terms "health care deliver" or" "quality improvement" were added to narrow results to those focused on practice settings (in-service) rather than preservice nursing education settings. This produced 3491 articles, of which 2546 unique studies were included for screening. No language or date restrictions were applied, and results were limited to studies with abstracts. Controlled vocabulary terms for each database were used and the terms for "nurs" and "mentor" were emphasized when possible. See Table 1 for further details.

Covidence online software was used to organize, screen, and review all articles [22]. See Fig. 1 for review flow diagram. The 2546 articles were screened first by title and abstract; articles were required to have abstracts and mention a variation of "nurse" and "mentor" in the title or abstract. We included abstracts that referred to mentoring as a focus or essential part of their intervention. Included abstracts either referred explicitly to inservice nurse mentoring programs, were reviews of such 
Table 1 Search strategy

\begin{tabular}{|c|c|c|c|}
\hline Database & Search terms & Results & $\begin{array}{l}\text { Without } \\
\text { duplicates }\end{array}$ \\
\hline PubMed & $\begin{array}{l}\text { (Mentors[mesh] OR mentoring[mesh] OR mentor*[tw]) AND (Nurses[mesh] OR nurs*[tw]) AND (Delivery of } \\
\text { Health Care[mesh] OR Healthcare Deliver*[tw] OR Health care deliver*[tw] OR Quality Improvement[mesh] OR } \\
\text { Quality Improvement*[tw])) }\end{array}$ & 1499 & \\
\hline EMBASE & $\begin{array}{l}\text { ('mentoring'/exp OR 'mentoring' OR 'mentor'/exp OR 'mentor' OR 'mentor*':ab,ti,kw) AND ('nurse'/exp OR } \\
\text { 'nurse' OR 'nurs*':ab,ti,kw) AND ('health care delivery'/exp OR 'health care delivery' OR 'total quality } \\
\text { management'/exp OR 'total quality management' OR 'quality improvement':ab,ti,kw OR 'health care deliver*': } \\
\text { ab,ti,kw OR 'healthcare deliver*':ab,ti,kw) AND [abstracts]/lim }\end{array}$ & 984 & 631 \\
\hline $\begin{array}{l}\text { CINAHL } \\
\text { Plus }\end{array}$ & $\begin{array}{l}\text { ((MM "Nurses+") OR nurs*) AND ((MM "Mentorship") OR mentor*) AND ((MH "Health Care Delivery+") OR } \\
\text { healthcare deliver* OR health care deliver*) OR ((MH "Quality Improvement+") OR quality improvement*)) }\end{array}$ & 513 & 326 \\
\hline $\begin{array}{l}\text { Web of } \\
\text { Science }\end{array}$ & $\begin{array}{l}\text { TS }=\left(\text { mentor }{ }^{*}\right) \text { AND TS }=\left(\text { nurs }^{*}\right) \text { AND TS }=(\text { delivery of health care* OR health care deliver* OR healthcare } \\
\left.\text { deliver* OR quality improvement }{ }^{*}\right)\end{array}$ & 111 & 13 \\
\hline Scopus & $\begin{array}{l}\text { (TITLE-ABS-KEY (mentor*) AND TITLE-ABS-KEY (nurs*) AND TITLE-ABS-KEY (("delivery of health care" OR "health- } \\
\text { care deliver*" OR "health care deliver*" OR "quality improvement*"))) }\end{array}$ & 277 & 30 \\
\hline Psychlnfo & $\begin{array}{l}\text { ((MM "Mentor") OR mentor*) AND ((MM "Nurses" OR MM "Psychiatric Nurses" OR MM "Public Health Service } \\
\text { Nurses" OR MM "School Nurses") OR (MM "Nursing") OR nurs*) AND ((DE "Health Care Delivery") OR (DE "Quality } \\
\text { of Care") OR delivery of health care* OR healthcare deliver* OR health care deliver* OR quality improvement*) }\end{array}$ & 107 & 47 \\
\hline Total & & & 2546 \\
\hline
\end{tabular}

programs, or were about nurse training or education interventions where mentoring formed a key part. Articles were excluded if nurses were not in mentor and mentee roles, or if they were about mentoring nursing students or faculty. Articles were excluded if they only referenced mentoring as a future recommendation. Articles were excluded if they were solely prospective or purely theoretical discussions of mentoring that did not reference implemented nurse mentoring. Narrative discussions about a single person's experience were excluded. Studies were excluded if they were about mentoring a mix of professions where nurses were the minority, mentoring a multidisciplinary team, or mentoring a project. Based on these criteria, 2327 articles were removed.

We reviewed the full text of 219 articles and applied the exclusion criteria from the first round of screening. Articles were excluded based on earlier criteria if the mentors were not exclusively nurses $(n=22)$ or if the focus was on training or education with minimal discussion of mentoring $(n=20)$. Likewise, articles were excluded if they referred to a poster or presentation session only $(n=44)$ or lacked online access $(n=22)$. Four articles about training mentors, and not about the mentoring process, were removed. One article was excluded because it was not in English, French, or Spanish. Any conflicts were resolved by authors' consensus. Using these criteria, 150 articles were excluded and 69 were included in the study.

Following the Arksey and O'Malley framework, we developed a table in Microsoft Excel to chart data about each article [20]. We included the article details, goal of the program, design features, program setting and size, and the format, frequency, and duration of mentoring contact. We also noted theoretical bases, the use of reflective practice, and the presence or absence of nonclinical mentoring. It was challenging to classify articles based on program geography. Using population estimates is difficult when comparing across countries where populations vary widely [23]. Given the limited information about program settings in many articles, we classified them into rural, urban, suburban, or a mix of settings based primarily on how authors identified the settings.

Consistent with the scoping review framework, this study does not attempt to make claims about the quality or weight of evidence. It is an overview of what is known about the research question based on each article. There were necessarily some subjective decisions made by the primary author about which themes to highlight. This was done in a reflexive manner in discussion among the authors. The authors of this paper represent diverse experience in nursing practice, public health practice and research, and policy research. This helped us develop a well-rounded understanding of in-service nurse mentoring literature.

\section{Results}

Of the 69 included articles, $65 \%(n=45)$ were published since 2010 . Only $3 \%(n=2)$ were published prior to 2000, 10\% $(n=7)$ between 2000 and 2005, and 22\% ( $n=$ 15 ) between 2006 and 2010. Articles were from 44 journals, 26 of which were nursing journals (determined by whether nursing was in the title). Sixteen of the included articles were about one of four mentoring programs; however, the articles focused on different iterations or facets of the interventions and mentoring was not always conducted in the same geographic areas. Because each article did not necessarily represent a distinct mentoring 


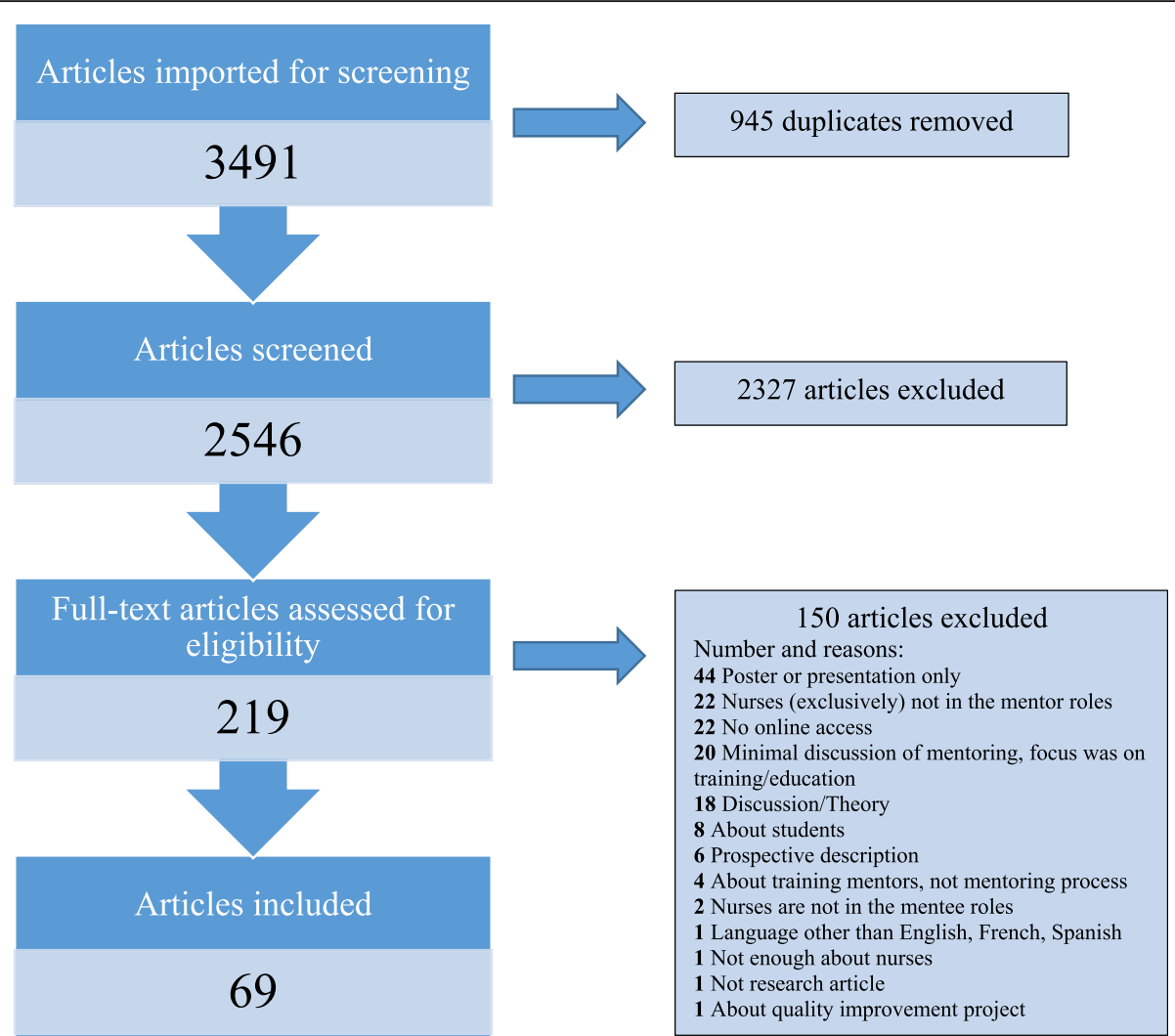

Fig. 1 Flow diagram. This represents each stage in the literature review process, including screening articles by title, abstract, and full text. Reasons for exclusion during full-text review are also included

program or activity, results are reported on a per article, rather than a per program, basis.

Articles were categorized by country based on author locations and location of program implementation, which were the same for most articles. See Fig. 2 for an overview of the literature by country. For any articles where this was different, studies were categorized based on the country in which the nurse mentoring program took place. Research was conducted in 11 low-income, middle-income, or high-income countries (i.e., Australia, Canada, India, Lesotho, Rwanda, South Africa, Spain, Sweden, United Kingdom, United States of America, and Zambia). In total, $67 \%(n=46)$ of the articles concerned programs in high-income countries. Nearly half of the studies $(n=33)$ were conducted in the United States. The next closest high-income country contributors were Australia $(n=5)$ and Canada $(n=4)$. Outside of the high-income countries, the countries contributing the most research were Rwanda $(n=9)$, India $(n=8)$, and South Africa $(n=4)$.

\section{Goals of the programs}

Structured categories for goals of the nurse mentoring programs were developed from themes that emerged during the screening and review process (Table 2).
Articles were sorted based on the primary purpose described for nurse mentoring, the most frequent of which was to strengthen a type of clinical care $(n=30)$. Among those articles, the most common types of clinical care targeted for improvement were maternal (including antenatal) and neonatal care $(n=10)$ and care for people living with the human immunodeficiency virus (HIV) ( $n$ $=7$ ). The next most common goals were to promote evidence-based practice $(n=11)$, promote retention $(n=$ $8)$, support new graduate nurse transition to practice ( $n$ $=8)$, and develop nurse leadership $(n=5)$.

\section{Setting, scale, and design of the programs}

Mentoring programs took place across a variety of settings and geographic areas. Articles were about programs in rural $(n=23)$, urban $(n=16)$, suburban $(n=$ $2)$, or a mix of settings $(n=11)$; with many articles $(n=$ 17) not providing this information. Most programs were in health care facilities and the majority of articles $(n=$ 55) specified the number of health care facilities in which mentoring occurred. Others took place within a health system and did not specify the number of facilities $(n=2)$. Additional articles were about public health or community settings $(n=2)$ or were based primarily on the location of the mentees $(n=2)$. For the 


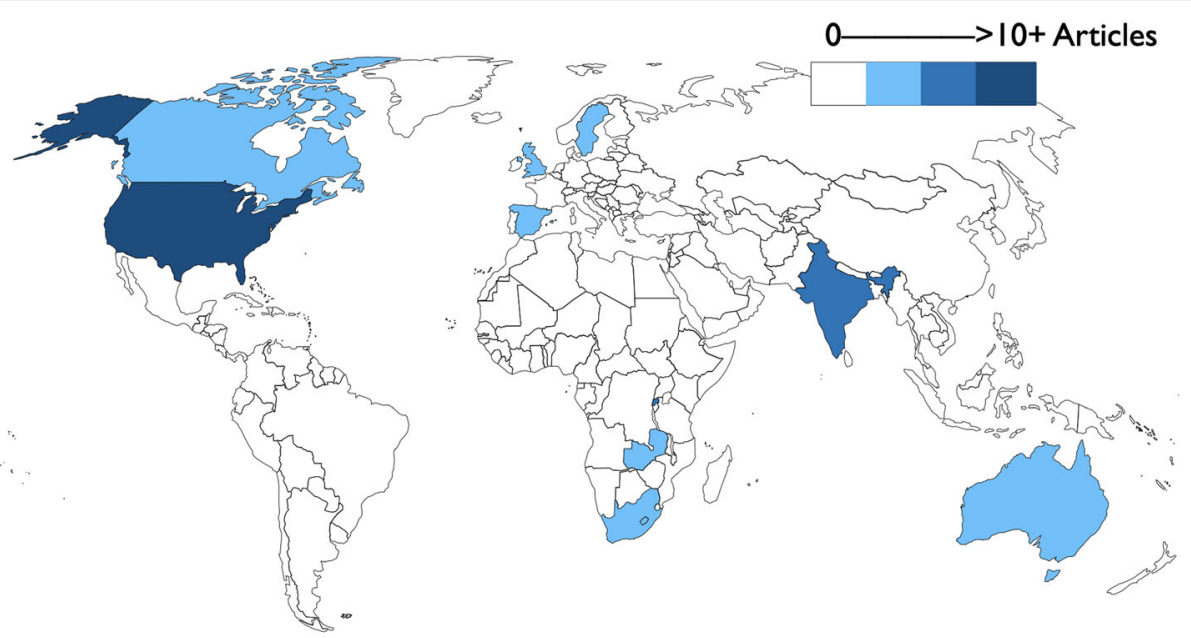

Fig. 2 Literature heat map. This map illustrates the geographic location (country) in which the study took place. Lighter colors represent fewer numbers of articles and darker colors represent greater numbers of articles

remaining articles $(n=8)$, the setting was unspecified or could not be determined based on the article. Nearly half of the articles $(n=30)$ were about programs developed internally to the setting where mentoring took place. The majority $(n=39)$ were about programs developed with external support, such as partnerships with academic institutions, nursing associations, and/or nonprofit organizations.

\section{Who were the mentors and mentees?}

Most of the articles described nurses in mentor roles as "experienced," "senior," "expert," or "graduate educated." A few studies $(n=5)$ either specifically chose mentors who were not in supervisory roles over mentees or included feedback from mentees who felt they could discuss more openly with non-supervisory mentors. But nearly as many articles $(n=4)$ used "nurse managers" or "charge nurses" as both supervisors and mentors.

Most of the papers $(n=42)$ described mentees as "staff nurses," "clinical nurses," "facility nurses," or similar. Additional articles $(n=17)$ reported programs specifically focused on newly graduated nurses new to clinical practice, new hires, or those re-entering the workforce. Several others $(n=10)$ described mentees as experienced nurses, leaders in practice settings, or advanced practice nurses. The programs focused on new graduates, new hires, or returning to work nurses were exclusively in high-income countries-the United States $(n=$ 15), Canada $(n=1)$, and Sweden $(n=1)$. Categorizing levels of nurse mentor and mentee education or experience was difficult because of the diversity among the program contexts. For example, a Bachelor of Science (BSc) is common entry-level education for nurses in many high-income countries while in low- and middle- income countries, often only managers or higher-level nurses have BSc education.

\section{How many mentors and mentees?}

Many of the 69 included articles did not specify the number of mentors $(n=40)$ or the number of mentees $(n=31)$ or these numbers could not be determined. In general, the numbers of mentors and mentees reported by the studies were fairly small, with 10 or fewer mentors and 50 or fewer mentees. Of the 29 articles which reported the number of mentors, $45 \%(n=13)$ were about programs with 10 or fewer mentors. Of the 38 articles which reported the total number of mentees, $66 \%(n=25)$ were about programs with 50 or fewer mentees. In some cases, articles reported a range (e.g., one to three mentees per health care facility) rather than a total number. For these articles, the range of possible mentees was calculated based on what the authors reported and the number of health care facilities. The median of this range was used to determine into which mentee size category to place the article.

\section{Frequency of contact}

Many studies did not specify the frequency of contact between mentors and mentees. It was either not addressed or reported as left to mentors and mentees to decide. For articles reporting on programs specifying frequency of contact $(n=38)$, the most common was at least once per month $(n=27)$ followed by at least once within 2 months $(n=10)$. A few studies $(n=4)$ reported only the total hours of mentoring time per mentee.

\section{Duration of mentoring}

The mentoring activities described varied greatly in duration. Many of the included studies $(n=19)$ did not 
Table 2 Overview of results

\begin{tabular}{|c|c|}
\hline Overview of results & Number of articles $(N=)$, percent of total $(\%)$ \\
\hline Goal of mentoring program & $N=69$ \\
\hline Strengthen a type of clinical care & $N=30(43 \%)$ \\
\hline Promote evidence-based practice & $N=11(16 \%)$ \\
\hline Promote retention & $N=8(12 \%)$ \\
\hline New graduate nurse transition to practice & $N=8(12 \%)$ \\
\hline Leadership development & $N=5(7 \%)$ \\
\hline Other & $N=7(10 \%)$ \\
\hline Scale of facility-based mentoring & $\begin{array}{l}N=5^{*} \\
{ }^{*} \text { Articles about facility-based mentoring }\end{array}$ \\
\hline One facility & $N=23(42 \%)$ \\
\hline 2-10 facilities & $N=11(20 \%)$ \\
\hline 10-50 facilities & $N=12(22 \%)$ \\
\hline 50-100 facilities & $N=4(7 \%)$ \\
\hline Over 100 facilities & $N=5(9 \%)$ \\
\hline Number of mentors & $N=69$ \\
\hline 0 to 10 & $N=13(19 \%)$ \\
\hline 10 to 50 & $N=8(11 \%)$ \\
\hline 50 to 100 & $N=4(6 \%)$ \\
\hline Over 100 & $N=4(6 \%)$ \\
\hline Unspecified/unable to determine & $N=40(58 \%)$ \\
\hline Number of mentees & $N=69$ \\
\hline 0 to 10 & $N=8(11 \%)$ \\
\hline 10 to 50 & $N=17(25 \%)$ \\
\hline 50 to 100 & $N=4(6 \%)$ \\
\hline Over 100 & $N=9(13 \%)$ \\
\hline Unspecified/unable to determine & $N=31(45 \%)$ \\
\hline Frequency of contact & $N=69$ \\
\hline Unspecified & $N=27(39 \%)$ \\
\hline At least once (some multiple) within 1 month & $N=27(39 \%)$ \\
\hline At least once (some multiple) within 2 months & $N=10(15 \%)$ \\
\hline Reported based on total hours or contact time & $N=4(6 \%)$ \\
\hline Other & $N=1(1 \%)$ \\
\hline Duration of mentoring & $N=69$ \\
\hline Under 3 months & $N=6(9 \%)$ \\
\hline 3 months to 6 months & $N=7(10 \%)$ \\
\hline 6 months to 1 year & $N=13(19 \%)$ \\
\hline 1 year or longer & $N=24(35 \%)$ \\
\hline Unspecified & $N=19(28 \%)$ \\
\hline
\end{tabular}

specify the duration of mentoring, or it could not be determined from the article. Of studies which did report on the duration of mentoring $(n=50)$, the length of time reported was less than 6 months $(n=13)$, between 6 months and 1 year $(n=13)$, or 1 year or longer $(n=24)$.

\section{Type of contact}

The high degree of variation in how the included studies described mentoring and the lack of clear description in many articles made it impossible to classify the studies into categories based on types of mentoring contact. Articles reported on in-person mentoring as well as 
distance mentoring or e-mentoring. Articles referenced individual mentoring, group mentoring, and a mix of both.

Fewer than half of the studies $(n=29)$ discussed the use of reflective practice as part of their programs. Among the programs using reflective practice, the most common description was the review of real cases or existing processes in the health facilities. Nurse mentees engaged in critical reflection to identify potentially flawed decision making and opportunities to improve care. Some articles $(n=5)$ discussed how mentees validated their decisions through discussions with their mentors or their peers.

Most of the studies $(n=36)$ described mentors providing only clinically focused mentoring. The articles which describe mentoring activities outside of a clinical focus $(n=33)$ mentioned social or other professional emphases. Social activities included mentors providing emotional support or socializing mentees into the working environment to supplement clinical learning [24]. One study emphasized the trust built through relationships between mentors and mentees as the foundation for mentee learning [25]. Professional activities included career advice and support, networking, and supporting nurse mentees to interpret and use research in their practice or create new research to build evidence-based practice.

\section{Theory}

We recorded which programs reported an explicit theoretical basis. Only six articles reported their mentoring programs to be based on established social theory. Of those, two referenced Benner's theory of novice to expert [26], two referenced Roger's theory of diffusion of innovations [27], one referenced Bandura's theory of self-efficacy [28], and one Gustafsson's SympathyAcceptance-Understanding-Competence model for confirming mentorship [29, 30]. While not a theoretical basis, an additional six articles referenced the World Health Organization's clinical mentoring guidelines for task-shifting for HIV prevention and treatment [31]; this included programs which were not about mentoring for HIV care delivery.

\section{Discussion}

The fact that $65 \%(n=45)$ of the articles included in this scoping review were published since 2010 demonstrates this is an emerging field of inquiry and programmatic experimentation. The geographic spread of the literature shows that interest emanates from high-income countries, and particularly the United States. This may be driven in part by more established traditions of nursing scholarship and advanced nursing education. However, this trend appears to be changing quickly. Rwanda,
India, and South Africa contributed 30\% $(n=29)$ of the included articles. Of those, 15 were published from 2015 to 2019. In Rwanda and India, this literature is based on large-scale nurse mentoring programs in rural settings implemented through partnerships between national or state governments and nonprofit organizations. There were multiple articles about different iterations of these programs or facets of the mentoring interventions. In Rwanda, the Mentoring and Enhanced Supervision at Health Centers (MESH) program was implemented by Partners in Health in partnership with the Rwandan Ministry of Health $[25,32-36]$. In India, programs were in Bihar and Karnataka states. CARE India has partnered with the Government of Bihar to implement a mobile nurse mentoring program and the AMANAT program whose various iterations have provided clinical mentoring for nurse midwives in more than 320 primary health centers [3, 37-40]. In Karnataka, the Karnataka Health Promotion Trust and international partners mentored nurses in up to 385 primary health centers to improve the quality of maternal and neonatal care [41-43]. Aside from the programs in Rwanda and India which were featured in multiple articles, two articles were about a nurse mentoring program to promote retention at the Banner Good Samaritan Medical Center in Phoenix, Arizona $[44,45]$.

Of articles which included information about the setting of the nurse mentoring programs, the most common locations were rural areas. In addition, the three large programs in Rwanda and India were all implemented in areas authors identified as rural. This suggests that practitioners view nurse mentoring as a suitable intervention to improve clinical knowledge and ability of rural nurses. This may be because rural nurses might have less access to training and continuing education than their urban counterparts.

The most frequently cited program goal across all articles was to strengthen clinical care, particularly antenatal, maternal, and neonatal care, and HIV care; emphases which may reflect either need and/or higher availability of resources for these types of care. Many of the programs were small and took place in one health facility. All five articles which reported on programs in over 100 health facilities were about programs in rural settings in the Indian states of Bihar and Karnataka. The size and location of these programs raise interesting considerations for the application of lessons from the body of literature on nurse mentoring. Most of the published articles are about programs in a few facilities in high-income countries, but the programs in the largest number of facilities in the world are in India, a lower middle-income country. The level of engagement and management support required to mentor nurses across hundreds of facilities in a low- or middle-income 
country with fewer resources and limited infrastructure is higher than what is needed to run a mentoring program in one or two facilities in the United States.

Many articles did not specify the number of mentors and mentees in their programs or the frequency of contact and duration of mentoring, which made it difficult to summarize and discuss similarities and differences across programs. We could not categorize levels of nurse mentor and mentee experience or education because of the diversity among the program contexts. In many high-income countries, Bachelor of Science (BSc) education is entry. However, in Rwanda, where nine of the articles were from, many nurses have only a secondary school nursing degree, though this is changing [32]. In the Indian states where the nurse mentoring programs were implemented and eight of the articles were from, there are two levels of nurse midwives with either 18 months or 3 years of post-secondary education [40].

There were clear disagreements about how authors used the terms "precepting," "mentoring," and "clinical supervision." Some specifically referred to preceptors as focused on clinical care and mentors on social support and personal growth [46-48]. Others referred jointly to "preceptorship-mentorship" roles [49]. Additional articles described the purposeful selection of mentors who were not in supervisory roles over mentees [42, 46, 5052 , while others noted that mentors were "nurse managers," "ward managers," or "charge nurses." [47, 53-56]

Following the scoping review framework for this research, we did not make determinations about the quality of each included article or weight of overall evidence for specific policies or interventions [20]. If authors reported on their program as a nurse mentoring program or referenced mentoring as a key part of an intervention, we included the study (if it met the other previously discussed inclusion criteria). This differentiates our study from a recent scoping review of mentorship of health personnel in low- and middle-income countries, which focused on mentoring programs designed to improve quality of care in primary health care settings and excluded studies that did not meet their definition of mentoring [4].

Our inclusive approach meant the term "mentoring" was used in a variety of ways. The varieties of "nurse mentoring" made summarizing them challenging, but also meant that articles describing unique programs were included. In two articles about a nurse mentoring program to increase nurse retention, the program paid the mentors monetary incentives if mentees remained in the workforce at specific points [44] [45]. Another program formed an academic-clinical partnership between a nursing school and a hospital where many of its graduates worked to provide a nurse faculty mentor known to the mentees during their initial weeks on the job [57].
One program used retired nurses as mentors for younger nurses [58]. Our thorough review of the nurse mentoring literature and inclusion of a variety of author perspectives and program designs provides a wellrounded overview of current knowledge about nurse mentoring.

\section{Limitations}

This study has several limitations. By choosing to include only articles about programs where nurses mentored other nurses, literature about interprofessional and multidisciplinary mentoring was excluded, which would have added alternate perspectives to the discussion, but made the dataset unwieldy. There were a number of articles about different facets of the same nurse mentoring programs or about iterations of the same program. We have attempted to manage this by describing those programs with multiple articles and their contributions clearly and reporting results on a per article rather than a per program basis. We attempted to reduce the risk of bias by defining clear criteria for selection of articles and thoroughly reviewing all articles at each level of the process. Any conflicts were discussed with co-authors to reach consensus. The total number of articles reviewed, particularly in the first screening stage, meant that decisions were made quickly based on the inclusion and exclusion criteria, which could have meant that some articles were overlooked.

\section{Conclusions}

This scoping review provides an overview of the current literature on in-service nurse mentoring. Despite the limitations of existing literature, our review identified some informative themes and trends. It was striking how many articles did not specify key features of programs, such as mentor to mentee ratios, frequency of contact, and duration of mentoring. To understand which models of nurse mentoring work best in different settings, practitioners and researchers must conduct and publish additional research targeting these gaps to make models of nurse mentoring more transparent and translatable. The research about programs in rural settings indicates that mentoring may be a particularly useful intervention to strengthen clinical care, where nurses are geographically dispersed and may have fewer opportunities for formal or informal education or training. While many of the articles were recent and mostly from highincome countries, the nurse mentoring programs in the largest number of facilities are not in those countries and are steadily contributing more to the literature. Research on these large programs can provide information to strengthen implementation of large or complex nurse mentoring programs in other settings. 
Nurse mentoring programs have the potential to strengthen the nursing workforce in a sustainable manner-from within the profession itself. By establishing what is known about in-service nurse mentoring and calling attention to remaining gaps, we hope this review will lead to new and groundbreaking research on workforce strengthening strategies that place nurses and midwives at the heart of responsive, people-centered health systems.

\section{Abbreviations \\ AMANAT: Emergency Obstetric and Neonatal Readiness (in Hindi) program; BSc: Bachelor of Science; HIV: Human immunodeficiency virus; \\ MESH: Mentoring and Enhanced Supervision at Health Centers program; PRIS MA: Preferred Reporting Items for Systematic Reviews and Meta-Analyses}

\section{Acknowledgements}

Not applicable

\section{Authors' contributions}

ADK and KDR conceived of this study and provided general guidance throughout. JH and ADK designed this study. JH, ADK, and ENR were responsible for the data collection, analysis, and interpretation. JH prepared the first draft of this manuscript and revised subsequent drafts. ADK, ENR, and KDR commented and provided feedback on the text. All authors read and approved the final manuscript.

\section{Funding}

Funding for this project was provided by the Bill and Melinda Gates Foundation. The funding source was not involved in data collection, analysis, or interpretation.

The contents in this article are those of the authors and do not necessarily reflect the view of the U.S. President's Emergency Plan for AIDS Relief, the U.S. Agency for International Development or the U.S. Government.

\section{Availability of data and materials}

The file generated by the data charting process and analyzed for this review are available from the corresponding author on reasonable request.

\section{Ethics approval and consent to participate}

Not applicable

\section{Consent for publication}

Not applicable

\section{Competing interests}

The authors declare that they have no competing interests.

\section{Author details}

${ }^{1}$ Credence Management Solutions, LLC, the Global Health Technical Professionals, USAID, 8609 Westwood Center Drive, Suite 300, Vienna, VA 22192, USA. ²Department of International Health, Johns Hopkins Bloomberg School of Public Health, 615 N Wolfe St, Baltimore, MD 21205, USA

Received: 10 February 2020 Accepted: 9 July 2020

Published online: 29 July 2020

\section{References}

1. World Health Organization. Global strategy on human resources for health: Workforce 2030 [Internet]. WHO. 2016. Available from: http://www.who.int/ workforcealliance/media/news/2014/consultation_globstrat_hrh/en/\%0A, http://apps.who.int/iris/bitstream/10665/250368/1/9789241511131-eng.pdf?ua =1\%5Cn, http://www.who.int/hrh/resources/pub_globstrathrh-2030/en/.

2. Lagarde $M$, Huicho L, Papanicolas I. Motivating provision of high quality care: It is not all about the money. BMJ. 2019;366(74).

3. Rao KD, Srivastava S, Warren N, Mayra K, Gore A, Das A, et al. Where there is no nurse: an observational study of large-scale mentoring of auxiliary nurses to improve quality of care during childbirth at primary health centres in India. BMJ Open. 2019;9(7):1-12.
4. Schwerdtle P, Morphet J, Hall H. A scoping review of mentorship of health personnel to improve the quality of health care in low and middle-income countries. Global Health. 2017;13(1):1-8.

5. Avortri GS, Nabukalu JB, Nabyonga-Orem J. Supportive supervision to improve service delivery in low-income countries: is there a conceptual problem or a strategy problem? BMJ Glob Heal. 2019;4(Suppl 9):e001151.

6. Rowe AK, Rowe SY, Peters DH, Holloway KA, Chalker J, Ross-Degnan D. Effectiveness of strategies to improve health-care provider practices in lowincome and middle-income countries: a systematic review. Lancet Glob Heal [Internet]. 2018;6(11):e1163-75 Available from: https://doi.org/10.1016/ S2214-109X(18)30398-X.

7. Semrau KEA, Hirschhorn LR, Delaney MM, Singh VP, Saurastri R, Sharma N, et al. Outcomes of a coaching-based WHO safe childbirth checklist program in India. N Engl J Med. 2017;377(24):2313-24.

8. Miller GE. The assessment of clinical skills/competence/performance. Vol. 65, Academic Medicine. 1990.

9. Leonard K, Masatu M. Professionalism and the know-do gap: exploring intrinsic motivation among health workers in Tanzania. Health Econ. 2010; 19(12):1461-77.

10. Crisp N, Iro E. Nursing Now campaign: raising the status of nurses. Lancet [Internet]. 2018;391(10124):920-1. Available from:. https://doi.org/10.1016/ S0140-6736(18)30494-X.

11. Nursing and Midwifery: Key Facts [Internet]. World Health Organization. 2018 [cited 2019 Nov 19]. Available from: https://www.who.int/news-room/ fact-sheets/detail/nursing-and-midwifery.

12. Naylor M, Volpe E, Lustig A, Kelley H, Melichar L, Pauly M. Linkages between nursing and the quality of patient care: a 2-year comparison. Med Care. 2013:51(4 SUPPL. 2):6-14.

13. Needleman J, Buerhaus P, Mattke S, Stewart M, Zelevinsky K. Nursestaffing levels and the quality of care in hospitals. N Engl J Med. 2002; 346(22):1715-22.

14. Aiken LH, Clarke SP, Cheung RB, Sloane DM, Silber JH. Educational levels of hospital nurses and surgical patient mortality. J Am Med Assoc. 2003; 290(12):1617-23.

15. Hayes LJ, O'Brien-Pallas L, Duffield C, Shamian J, Buchan J, Hughes F, et al. Nurse turnover: a literature review. Int J Nurs Stud. 2006;43(2):237-63.

16. Kurth AE, Jacob S, Squires AP, Sliney A, Davis $S$, Stalls $S$, et al. Investing in nurses is a prerequisite for ensuring universal health coverage. J Assoc Nurses AIDS Care [Internet]. 2016;27(3):344-54. Available from:. https://doi. org/10.1016/j.jana.2016.02.016.

17. Andrews M, Wallis M. Mentorship in nursing: a literature review. J Adv Nurs. 1999:29(1):201-7.

18. Waters D, Clarke M, Ingall AH, Dean-Jones M. Evaluation of a pilot mentoring programme for nurse managers. J Adv Nurs. 2003;42(5):516-26.

19. Mills JE. Francis K, Bonner A. Mentoring, clinical supervision and preceptoring: clarifying the conceptual definitions for Australian rural nurses. A review of the literature. Rural Remote Health. 2005:5:1-10.

20. Arksey H, O'Malley L. Scoping studies: towards a methodological framework. Int J Soc Res Methodol Theory Pract. 2005;8(1):19-32.

21. Moher D, Liberati A, Tetzlaff J, Altman DG, Altman D, Antes G, et al. Preferred reporting items for systematic reviews and meta-analyses: the PRIS MA statement. PLoS Med. 2009;6(7).

22. Covidence systematic review software. Melbourne, Australia: Veritas Health Innovation;

23. The World Bank. A recommendation on the method to delineate cities, urban, and rural areas for international statistical comparisons. Vol. 3. 2020.

24. Jones SJ. Establishing a nurse mentor program to improve nurse satisfaction and intent to stay. J Nurses Prof Dev. 2017;33(2):76-8.

25. Manzi A, Magge H, Hedt-Gauthier BL, Michaelis AP, Cyamatare FR, Nyirazinyoye L, et al. Clinical mentorship to improve pediatric quality of care at the health centers in rural Rwanda: a qualitative study of perceptions and acceptability of health care workers. BMC Health Serv Res. 2014;14(1).

26. Benner P. From novice to expert: excellence and power in clinical nursing practice. Menlo Park, CA: Addison-Wesley; 1984

27. Rogers EM. Diffusion of Innovations. 5th ed. New York, NY: Free Press; 2003.

28. Bandura A. Social Learning Theory. Englewood Cliffs, NJ: Prentice-Hall; 1977.

29. Gustafsson B. The SAUC model for confirming nursing, an action-theoretic approach to theory building and nursing practice. J Nurs Theory. 2000;9(1): 6-21

30. Gustafsson G. Confirming Nursing. The SAUC Model for Health and Community Care. 2nd ed. Lund, Sweden; 2005. 
31. World Health Organization. WHO recommendations for clinical mentoring to support scale-up of HIV care, antiretroviral therapy and prevention in resource-constrained settings [Internet]. 2005. Available from: https://www who.int/hiv/pub/quidelines/clinicalmentoring.pdf?ua $=1 \% 0 \mathrm{~A}$, http://www. who.int/hiv/pub/guidelines/clinicalmentoring.pdf.

32. Anatole $M$, Magge $H$, Redditt $V$, Karamaga A, Niyonzima S, Drobac $P$, et al. Nurse mentorship to improve the quality of health care delivery in rural Rwanda. Nurs Outlook [Internet]. 2013;61(3):137-44. Available from:. https:// doi.org/10.1016/j.outlook.2012.10.003.

33. Magge H, Anatole M, Cyamatare FR, Mezzacappa C, Nkikabahizi F, Niyonzima S, et al. Mentoring and quality improvement strengthen integrated management of childhood illness implementation in rural Rwanda. Arch Dis Child. 2015;100(6):565-70.

34. Manzi A, Nyirazinyoye L, Ntaganira J, Magge $H$, Bigirimana $E_{\text {, }}$ Mukanzabikeshimana $L$, et al. Beyond coverage: improving the quality of antenatal care delivery through integrated mentorship and quality improvement at health centers in rural Rwanda. BMC Health Serv Res. 2018; 18(1):1-8.

35. Ndayisaba A, Harerimana E, Borg R, Miller AC, Kirk CM, Hann K, et al. A clinical mentorship and quality improvement program to support health center nurses manage type 2 diabetes in Rural Rwanda. J Diabetes Res. 2017;2017.

36. Smith S, Kayiteshonga Y, Misago C, lyamuremye JD, Dusabeyezu J. d'Arc, Mohand $A$, et al. Integrating mental health care into primary care: the case of one rural district in Rwanda. Intervention. 2017;15(2):136-50.

37. Das A, Nawal D, Singh MK, Karthick M, Pahwa P, Shah MB, et al. Evaluation of the mobile nurse training (MNT) intervention - a step towards improvement in intrapartum practices in Bihar. India. BMC Pregnancy Childbirth. 2017;17(1):1-12.

38. Ghosh R, Spindler H, Morgan MC, Cohen SR, Begum N, Gore A, et al. Diagnosis and management of postpartum hemorrhage and intrapartum asphyxia in a quality improvement initiative using nurse-mentoring and simulation in Bihar. India. PLoS One. 2019;14(7):e0216654.

39. Morgan MC, Dyer J, Abril A, Christmas A, Mahapatra T, Das A, et al. Barriers and facilitators to the provision of optimal obstetric and neonatal emergency care and to the implementation of simulation-enhanced mentorship in primary care facilities in Bihar, India: a qualitative study. BMC Pregnancy Childbirth. 2018;18(1):1-14.

40. Raney JH, Morgan MC, Christmas A, Sterling M, Spindler H, Ghosh R, et al. Simulation-enhanced nurse mentoring to improve preeclampsia and eclampsia care: an education intervention study in Bihar. India. BMC Pregnancy Childbirth. 2019;19(1):1-9.

41. Jayanna K, Bradley J, Mony P, Cunningham T, Washington M, Bhat S, et al. Effectiveness of onsite nurse mentoring in improving quality of institutional births in the primary health centres of high priority Districts of Karnataka, South India: A cluster randomized trial. PLoS One. 2016;11(9):1-18.

42. Fischer EA, Jayana K, Cunningham T, Washington M, Mony P, Bradley J, et al. Nurse mentors to advance quality improvement in primary health centers: lessons from a pilot program in Northern Karnataka. India. Glob Heal Sci Pract. 2015;3(4):660-75.

43. Bradley J, Jayanna K, Shaw S, Cunningham T, Fischer E, Mony P, et al. Improving the knowledge of labour and delivery nurses in India: a randomized controlled trial of mentoring and case sheets in primary care centres. BMC Health Serv Res. 2017;17(1):1-9.

44. Hurst S, Koplin-Baucum S. Role acquisition, socialization, and retention. J Nurses Staff Dev. 2003;19(4):176-80.

45. Hurst SM, Koplin-Baucum S. Innovative solution: mentor program: evaluation, change, and challenges. Dimens Crit Care Nurs. 2005;24(6):273-4.

46. Beecroft PC, Santner S, Lacy ML, Kunzman L, Dorey F. New graduate nurses' perceptions of mentoring: six-year programme evaluation. J Adv Nurs. 2006; 55(6):736-47.

47. DeSimone BB. Perceptions of leadership competence between interns and mentors in a cooperative nurse internship. Nurse Educ. 1999;24(4):21-5.

48. Greene MT, Puetzer M. The value of mentoring: a strategic approach to retention and recruitment. J Nurs Care Qual. 2002;17(1):63-70.

49. Scott-Herring $M$, Singh S. Development, implementation, and evaluation of a certified registered nurse anesthetist preceptorship-mentorship program. J Contin Educ Nurs. 2017;48(10):464-73.

50. Rapala K. Mentoring staff members as patient safety leaders: the Clarian Safe Passage Program. Crit Care Nurs Clin North Am. 2005;17(2):121-6.
51. Zucker B, Goss C, Williams D, Bloodworth L, Lynn M, Denker A, et al. Nursing retention in the era of a nursing shortage. Worldviews Evidence-Based Nurs. 2007;4(3):172.

52. Ronsten B, Andersson E, Gustafsson B. Confirming mentorship. J Nurs Manag. 2005;13(4):312-21.

53. Jinks AM, Tabernacle B, Kenny C. Evaluation and action improving care for older people in an acute hospital setting. Pract Dev Heal Care. 2009; 8(January):18-27.

54. Hegeman C, Hoskinson D, Munro H, Maiden P, Pillemer K. Peer mentoring in long-term care. Gerontol Geriatr Educ. 2008;28(2):77-90.

55. Boettcher PA, Hunter RB, McGonagle P. Using lean principles of standard work to improve clinical nursing performance. Nurs Econ [Internet]. 2019; 37(3):152-158,163. Available from: http://ezproxy.laureate.net.au/login?url = https://search.proquest.com/docview/2243308672?accountid = 176901 .

56. Williams AK, Parker VT, Milson-Hawke S, Cairney K, Peek C. Preparing clinical nurse leaders in a regional Australian teaching hospital. J Contin Educ Nurs. 2009:40(12):571-6.

57. Hayes J, Scott AS. Mentoring partnerships as the wave of the future for new graduates. Nurs Educ Perspect. 2007;28(1):27-9.

58. Mcdonald G, Mohan S, Jackson D, Vickers MH, Wilkes L. Continuing connections: the experiences of retired and senior working nurse mentors. $J$ Clin Nurs. 2010;19(23-24):3547-54.

\section{Publisher's Note}

Springer Nature remains neutral with regard to jurisdictional claims in published maps and institutional affiliations.
Ready to submit your research? Choose BMC and benefit from:

- fast, convenient online submission

- thorough peer review by experienced researchers in your field

- rapid publication on acceptance

- support for research data, including large and complex data types

- gold Open Access which fosters wider collaboration and increased citations

- maximum visibility for your research: over $100 \mathrm{M}$ website views per year

At BMC, research is always in progress.

Learn more biomedcentral.com/submissions 